Erratum

\title{
Erratum: Khan, M.O.; et al. A Load Flow Analysis for an AC/DC Hybrid Distribution Network Incorporated with Distributed Energy Resources for Different Grid Scenarios. Energies, 2018, 11, 367
}

\author{
Muhammad Omer Khan, Saeed Zaman Jamali, Chul-Ho Noh, Gi-Hyeon Gwon and \\ Chul-Hwan Kim * \\ College of Information and Communication Engineering, Sungkyunkwan University, Suwon 440-746, Korea; \\ omerkhan@skku.edu (M.O.K.); saeedzaman@skku.edu (S.Z.J.); chcoo87@skku.edu (C.-H.N.); \\ elysium03@skku.edu (G.-H.G.) \\ * Correspondence: chkim@skku.edu; Tel.: +81-31-290-7124
}

Received: 11 April 2018; Accepted: 16 April 2018; Published: 19 April 2018

The authors wish to make the following changes to their paper [1]. A modification to one of the authors' name, correct contribution and authorship are shown below:

Muhammad Omer Khan, Saeed Zaman Jamali, Chul-Ho Noh, Gi-Hyeon Gwon and Chul-Hwan Kim * College of Information and Communication Engineering, Sungkyunkwan University, Suwon 440-746, Korea; omerkhan@skku.edu (M.O.K.); saeedzaman@skku.edu (S.Z.J.); chcoo87@skku.edu (C.-H.N.); elysium03@skku.edu (G.-H.G.)

*Correspondence: chkim@skku.edu; Tel.: +81-31-290-7124

Author Contributions: Muhammad Omer Khan proposed the original idea and carried out the main research tasks. Saeed Zaman Jamali, Chul-Ho Noh and Gi-Hyeon Gwon contributed to analyzing, writing and summarizing the proposed ideas. Saeed Zaman Jamali and Chul-Hwan Kim double-checked the results and the whole manuscript.

We apologize for any inconvenience caused to the readers by these changes. The change does not affect the scientific results. The manuscript will be updated and the original will remain online on the article webpage.

\section{Reference}

1. Khan, M.O.; Jamali, S.Z.; Noh, C.-H.; Gwon, G.-H.; Kim, C.-H. A Load Flow Analysis for AC/DC Hybrid Distribution Network Incorporated with Distributed Energy Resources for Different Grid Scenarios. Energies $2018,11,367$.

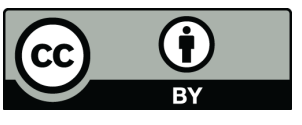

(C) 2018 by the authors. Licensee MDPI, Basel, Switzerland. This article is an open access article distributed under the terms and conditions of the Creative Commons Attribution (CC BY) license (http://creativecommons.org/licenses/by/4.0/). 